\title{
SMALL EFEORTS, BIG RESULTS: IMPACT OF AWARENESS AND TRAINING BY DIABETES EDUCATORS ON TIDM PATIENTS
}

\section{BACKGROUND}

I am Praveen and I have had Type1 diabetes for last 30 years. I was devastated after the diagnosis. I was admitted 3 times with ketoacidosis in the initial 2 years of my diabetes.

I joined a non-government organization called "Society for Prevention and Awareness of Diabetes" (SPAD) dedicated towards spreading diabetes awareness among patients and society - funded by likeminded people. Eventually I established a separate wing for people with Type1 diabetes.

Later, a diabetes educator, Mrs. Ranjana, joined me. We worked together with SPAD to train people with T1DM. We gradually expanded the team to 12 members.

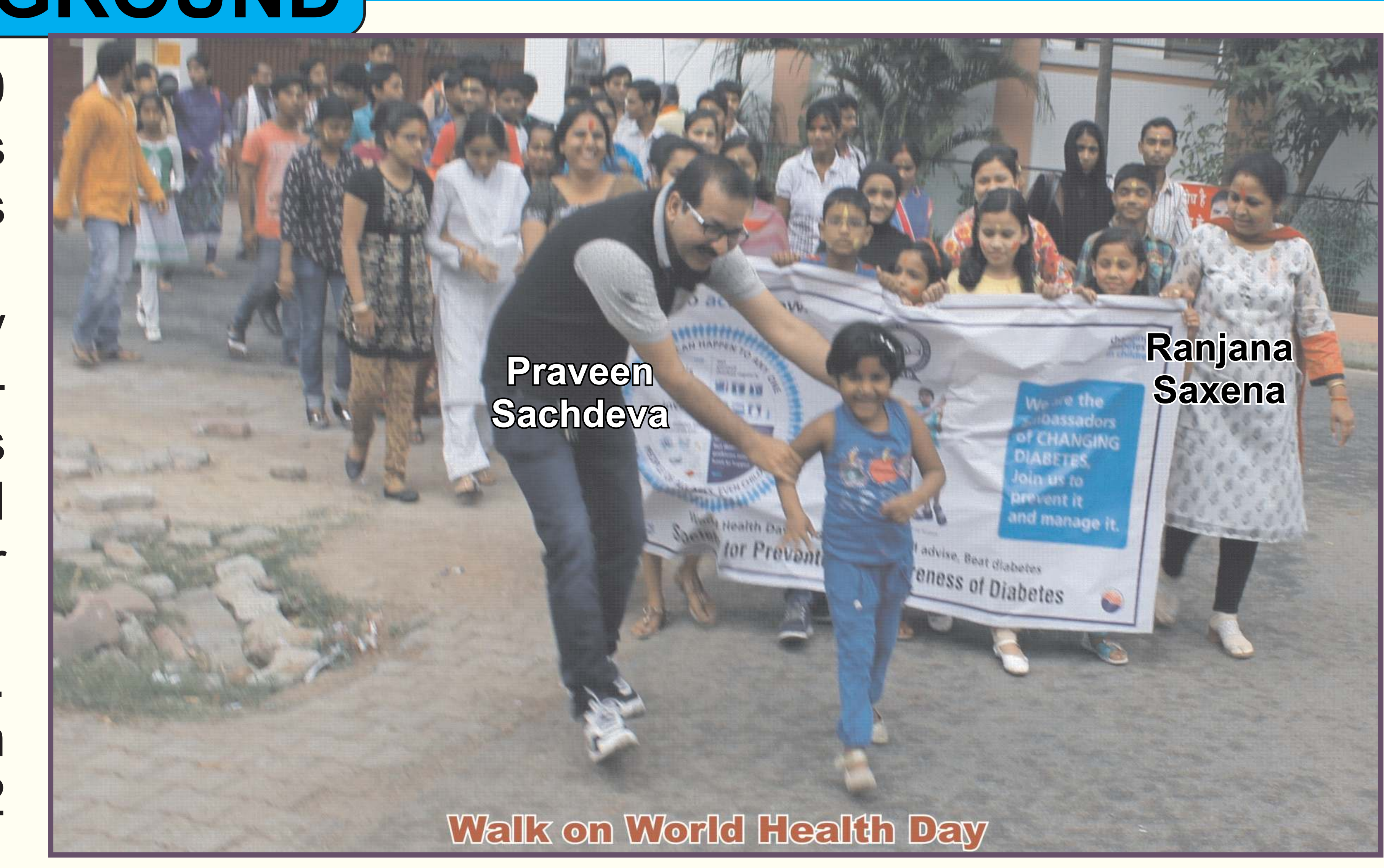

AlM

The impact of diabetes education and awareness (by educators) on acute diabetes complications and awareness among T1DM patients.

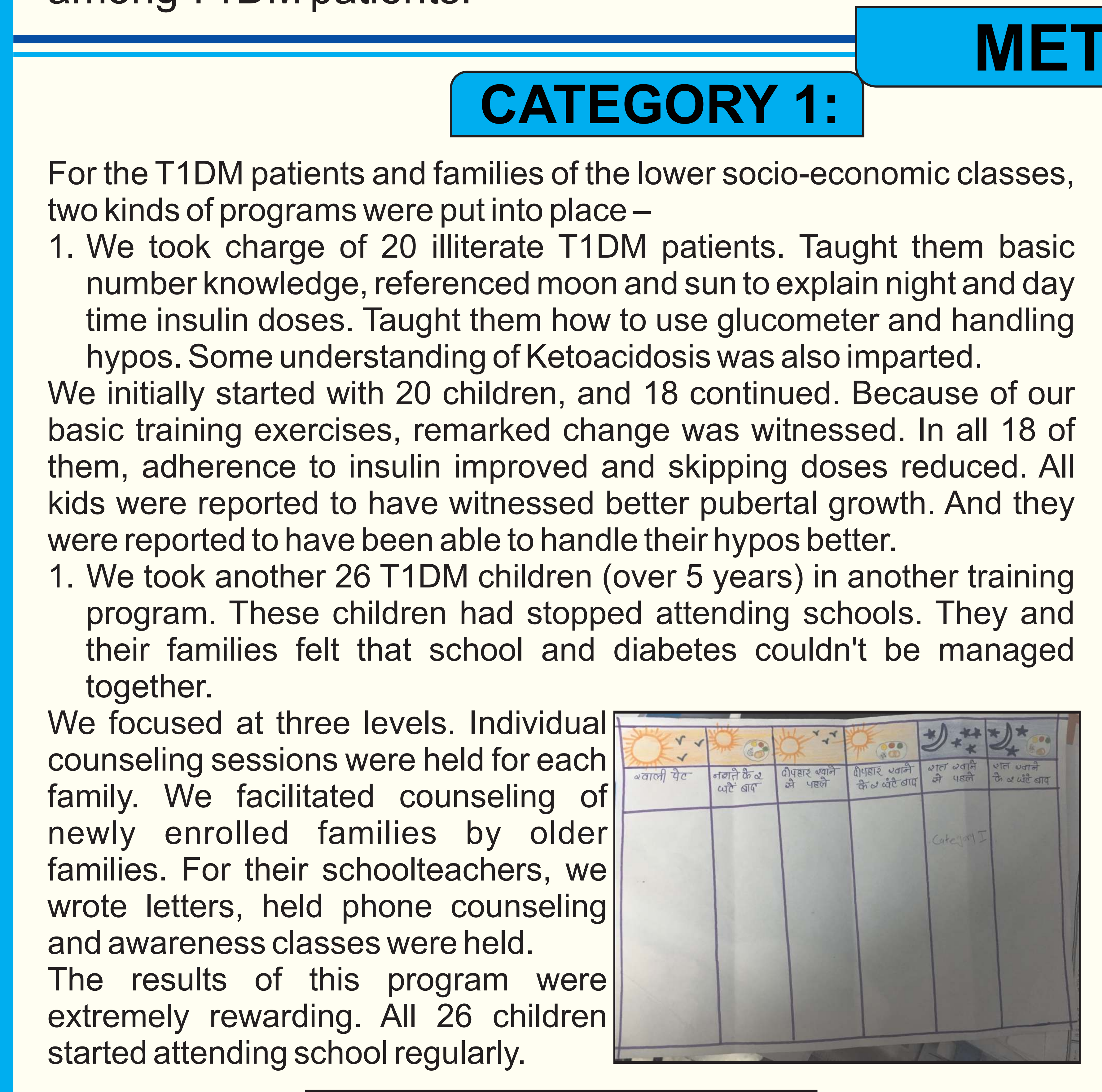

\section{RESULTS}

1. Under privileged children became independent.

2. T1DM children from low socio economic strata who stopped attending school, started attending.

3. Reduced incidences of hypoglycemia and ketoacidosis

4. Education brought confidence leading to independence among secular group of patients.

5. The society became sensitized to T1DM.

\section{CATEGORY 2:}

For the T1DM patients and families of a more secular socio-economic class, two types of programs were put into place-

1. We started counseling routine T1DM patients on regular basis. Later parents were also involved. Small group meetings of families and T1DM children were then organized.

Our program included 100 children and their families. During the first 5 years: out of the $100-4$ or 5 of them were reported to have needed hospital admission every year. But because of the counseling program, during the last 7 years - the annual hospital admission rate has gone down to 0 or 1 .

1. We undertook a set of programs aimed at increasing awareness in society at large (within Kanpur)

Every year we conduct 4 programs - combining education and recreation. We've conducted 76 programs over past 19 years. Each program involved two educators, T1DM experts (1-3) and eminent person from society. The outcomes have been - reduction in episodes of hypoglycemia, diabetic ketoacidosis and diabetes distress; building up of self-confidence.

We organized India's first T1DM Meeting. It was a 2-day meeting for people with T1DM to discuss contemporary and pressing issues related to T1DM with lots of interactions. 422 T1DM people and experts participated from India.

We conducted social events to spread awareness and battle the stigma in society regarding T1DM. The group performed plays to spread awareness about - mandatory use of insulin, hypoglycemia, sick day rules, herbal medicines, diabetic ketoacidosis, marriage and diabetes. We also organized the world's first of its kind fashion show for T1DM people.

\section{DISCUSSION}

Our team has over 20 years of experience. We along with SPAD have made a difference to the lives of T1DM people and their families - coming from all classes of society. As functioning in India - which doesn't have any organized infrastructure to spread awareness and train T1DM patients, we strongly recommend our model be used in resource-poor settings across the globe 